\title{
Reflective Journal Writing: Writing Processes Applied by Skilful and Less Skilful EFL Graduate Students
}

\author{
S. Arifin ${ }^{*}$ iD \\ ${ }^{1}$ English Graduate Program Universitas Muhammadiyah Prof. Dr. Hamka (Uhamka) Jakarta, Indonesia \\ *Corresponding author: syaadiah.arifin@uhamka.ac.id
}

\begin{abstract}
Reflective writing (RW) is one of the most common writing activities adopted by higher education students. However, some still struggle with this writing technique. Therefore, this study aims to analyze the appropriate process/sub-process used by skilled and less skilled EFL graduate students in doing Reflective writing. Data were collected from 2 (two) post-graduate students through think-aloud, observation, retrospective, and semi-structured interviews. The instrument used to collect data is a questionnaire. The data analysis technique used is descriptive qualitative and quantitative analysis. The result of the research is some students have difficulty in reflective writing. A helpful solution is to encourage students to practice writing in various contexts under different environments and receive ongoing training supported by the teacher. The importance of integrating a focus on effective writing processes/sub-processes in academic writing and encouraging students to practice Reflective essays in various contexts by reading extensively while writing reflections. In addition, when the reflection writing task is carried out regularly, it helps students to have adequate knowledge of essential concepts and critically understand them.
\end{abstract}

Keywords: Reflective Writing, Writing Processes, EFL

\begin{tabular}{|c|c|c|}
\hline History: & & Publisher: Undiksha Press \\
\hline Received & : September 09, 2021 & Licensed: This work is licensed under \\
\hline Revised & : September 12, 2021 & a Creative Commons Attribution 3.0 License \\
\hline Accepted & : October 09, 2021 & (c) (†) () \\
\hline Published & : October 25, 2021 & (c) \\
\hline
\end{tabular}

\section{INTRODUCTION}

Journal writing is the process of recording personal insights, reflections, and questions on assigned topics (Abednia et al., 2013; Anderson et al., 2021). It is extensively applied in the educational setting as an individual activity with diverse terms and these include journal dialogue, learning journals, and reflective writing (RW) (Hashemi \& Mirzaei, 2015; Thevasigamoney \& Yunus, 2014). Several studies provided strong indications that RW is commonly used to nurture critical thinking and reflection as well as promote creativity (Arter et al., 2016; Stanton \& Stanton, 2017). It analytically evaluates ones' perceptions and theories and encourages students to be active (Bahmani, 2016). This writing type also develops a relationship between course materials and experiences. Reflective journal writing is a cognitive activity that allows writers to express themselves, reflect on their experiences, and assess their knowledge. This process involves several stages, namely planning, drafting or translating, and reviewing (Amrina \& Sundari, 2021; Pen et al., 2020).

However, a concise analysis of the writing processes adopted by skilled and less skilled EFL undergraduates was explored in this research. Previous studies reported that the participants were usually given a specific writing topic, to be completed within a fixed time, usually 30 to 60 minutes. In this research, the respondents were given a broad topic, which was narrowed down to attributes that specifically prompted their interest. In addition, there was no limitation on the length of writing and duration because they also had to type their work on a computer/laptop. Furthermore, it analyzes some of the crucial roles played by RW by comparing the writing processes adopted by both skilled and less-skilled writers. Primary data were collected by using the traditional method and Think-Aloud Protocols (TAPs) 
inherent in the Zoom application. All products used to carry out the assignments were computer-based, which provided unobtrusive, simple, and more reliable writing processes compared to those applied in preliminary studies. Subsequent sections discussed reflective writing and briefly analyzed the cognitive model before discussing prior processes.

Reflective writing aims to determine an individual's learning skills, the ability to critically review certain topics, build a theory from observations, hesitantly engage in discussions, and self-development (Cheng \& Chan, 2019; Pen et al., 2020). Reflection usually entails looking back or examining previous tasks and is also defined as an afterthought activity (Bjerkvik \& Hilli, 2019; Szenes \& Tilakaratna, 2021). Reflective writing is written systematically, based on a distinct purpose, asserting basic observations, and presenting additional information (Farahian et al., 2021; Weaver \& Mulgrew, 2021). Meanwhile, these are all parts of the process that develops reflective writing. However, some students without much knowledge of academic writing usually encounter difficulties, which led to the conscious development of reflection to generate thoughtful writings. One of the effective ways to improve this capacity is through frequent practices in multiple contexts, including comprehensive and consistent training (Caravella \& Johnson, 2019).

Previous process-oriented research is often concerned with processes and strategies (sub-processes) adopted when writing L2 (Abdel Latif, 2019; Liu, 2015). Some studies compared the techniques used by the students in L1 and L2 (Alkubaidi, 2018; Johnson, 2020). The similarities and differences between these writing processes (Wang, 2012: Chu et al., 2019). The transferability issues from L1 to L2 or vice versa are still debatable (Guo \& Huang, 2018; Iman, 2020; Wei, 2020). Several preliminary studies have also analyzed the problems encountered during these writing processes. An innovative way to acquire data due to the complexity of the think-aloud instructions (Wingate \& Harper, 2021). They used an application installed in the computer or laptop called "screen capture software Ice cream". This recording software is obtrusive, and at the same time, provides a comprehensive and accurate account of all activities conducted on the system, such as information searches. Students also make use of grammatical applications or other facilities installed on the computer.

However, in this study, the students applied think-aloud protocols when writing. The skilled and less skilled ones carried out all activities on their laptops. In addition, each of them verbalized the written topic during the Zoom meeting. All activities were recorded and executed in a day, although they read some articles on Autonomy Learning before starting the actual procedure. Therefore, this study aims to analyze the appropriate process/subprocess used by skilled and less skilled EFL graduate students in doing Reflective writing.

\section{METHODS}

This qualitative study focuses on the writing processes applied in RW. Meanwhile, in the first semester of the 2020/2021 academic year, 12 students registered for the course "Approaches and Methods in TESOL". They were given an assignment on RW once in two weeks, through this procedure, it is expected that they steadily improve their reflective capability. The students were monitored shortly before their first assignment till the third one, and each task was discussed in class. Based on the thorough observation by the lecturer, they still encountered certain difficulties when working on the initial assignment. After practicing this type of writing severally, they were able to develop their level of critical reflection. However, this varies among students, for example, SW1's performance was constantly improved while SW2 only achieved non-reflection and understanding levels. These two undergraduates were purposively selected because they met the research criteria, namely skilled and less skilled writers. Some data sources were adopted in analyzing 
the writing processes. The first method was Think-aloud Procedures (TAPs) and writing process observation through Zoom meeting, recording the participants' activities during the entire assignment production. The third and final approaches were the retrospective and open-ended interviews regarding these tasks. As previously reported, TAPs have several limitations. To anticipate the students' varying abilities to acquire data, they needed to practice rigorously before carrying out the TAPs. The topic "autonomy learning" was the students' fourth assignment, executed during the zoom meeting by SW1 and SW2.

$A$ reflection task is an individual activity assigned by a lecturer regarding a particular topic, such as an internship, observation, or volunteer experience. The most crucial part is that it cites the writer's reactions, opinions, suggestions, feelings, and analysis of an experience in a more personal manner compared to a formal study or analytical essay. Reflective tasks take several forms. For example, the lecturer tends to ask the students to write about today's lesson quickly or simply summarize the writer's article at the end of the class. This has to be organized as a formal essay (descriptive reflection). It needs to start with an introduction, the thesis statement, several paragraphs, and a conclusion. This type of reflective writing was applied in this study. The students (SW1 and SW2) were given a day to complete their writing tasks at their convenience. Moreover, conducting think-aloud is a tiring activity, it tends to ruin their concentration when it is done for a long time. Students recorded all their activities during the Zoom meeting, which was reported in this research. The writing processes were observed and unclear information jotted and discerned during the retrospective interview. The final instrument was an open-ended interview which consisted of 10 items. Several questions were asked, such as their experiences and problems encountered when writing a reflective journal, applying TAPs, and issues encountered when completing their tasks through zoom meeting.

The students' writing process was thoroughly observed by watching their recorded activities during the Zoom meeting and jotting down everything that happened in each stage. A retrospective interview was also conducted, where certain unclear questions were asked. The data were then transcribed for content analysis. The acquired information was often coded according to a specific classification reported in this research throughout the process. The open-ended interviews were examined thematically and further coded independently, besides ten items were questioned.

\section{RESULTS AND DISCUSSION}

\section{Results}

SW1 and SW2 had already read several reputable articles or journals of interest as well as reflected on past events (experiences, discussions held with their peers and lecturers) or their background knowledge to support their claims on autonomy learning. They had to narrow it down into specific topics. SW1 discussed "The relationship between motivation and autonomy learning". On the contrary, SW2 worked on "Autonomy Learning in Digital Era". SW1 and SW2 spent relatively 74 minutes and 61 minutes completing their respective tasks. The length of their writing also varied SW1 and SW2 wrote 644 and 475 words, respectively. SW1 anticipated the topic to be written and referred to the overall plan throughout the process. SW1 keenly reflected on ideas from articles and past experiences regarding the content and wrote it as a guideline. SW1 often paused to think and ensure their work was organized. This respondent planned to write 4 paragraphs, including introduction, body paragraphs, and conclusion. However, SW2 tried to relate to previously read articles and went ahead to engage in reflective writing with slight planning. In the introductory aspect, SW1 tried to recall their background knowledge of autonomy learning and relate it to 
previously read articles, and past experiences (discussions with the lecturer, friends, and colleagues)..........pauses awhile to reflect....

........ One of the essential elements of an autonomous learner is motivation. However, many teachers are frustrated by their demotivated students. They are not aware of the important connection between motivation and self-determination. Motivation is related to whether or not students have opportunities to be autonomous and make relevant academic choices. ............Finally, SW1 wrote the thesis statement, "The Relationship between Motivation and Autonomy Learning" (172 words). SW2 only discussed the definitions of autonomy learning and related it to the digital era. Autonomy Learner in Indonesian is interpreted as independence in teaching and learning activities (self-study)...... Gagne (1985) defines learning as "a change in human disposition or capability which persists over a period of time..........

...... During the Covid-19 Pandemic, students were forced to learn independently. In addition, the teachers were mandated to provide interesting teaching and learning activities. The Covid-19 pandemic has had both positive and negative impacts. In view of the educational system, teachers are supposed to provide interesting and creative materials as well as ensure that the students do not feel bored. They were expected to recreate the curriculum, assessment system, and regulations in this digital era... (158 words). In the body paragraphs, SW1 elaborated on certain points. The first is to instill motivation, according to Holec (1981), "Learner autonomy based on reflection and taking responsibility for one's learning processes has become a central concern in the recent history of language teaching".......paused while reflecting on some issues. However, it is not easy to discipline students as some are uncontrollable, at least in the school where I teach. One of the ways to motivate students is to take responsibility and get them involved in classroom activities. Secondly, SW1 usually appreciates students that take their assignments seriously because it encourages them. Appreciation is in the forms of praises, rewards, good scores, etc..... therefore, they tend to put in more effort. Therefore, at least 2 effective ways are used to make students learn independently at home. First, they need to be motivated and appreciated. This method has been practiced by me when teaching high school students. It was realized that motivating students to be autonomous learners was a difficult task, although giving them a simple and interesting assignment at the beginning of the class and consistently monitoring their improvement while they work independently helps a lot. Secondly, appreciating them... (472).

SW2 only grouped some aspects of autonomy learning, namely the self-study program (along with the independence level, autonomy learning model, and learner). This was written without any revision or proofreading. It seemed SW2 memorized previously read articles, although SW2 could not describe these experiences in detail. This condition led to certain limitations in their reflective abilities. SW1's writing process turned out to be nonlinear, involving a continuous interplay of thinking, planning, and reviewing during the entire procedure. These activities are the most important components needed to improve the writing quality. SW1 often paused to reflect on the planning purposes, besides, there were frequent reviews as SW1 continued with the written text production. Furthermore, the various stages were also revised. SW1 was considered a skilled writer judging from their behaviour. Some discrete variations were observed between SW1 and SW2. According to the recording observation, SW1 was able to deliberately and simply control and direct the entire process by understanding the nature of writing, which is a recursive procedure. However, SW2 was unaware of this fact which involves generating ideas and reviewing the text to discover its intended meaning. SW2 revealed a lack of control and direction and often lost concentration when writing the body paragraphs. In addition, SW2 slightly planned and revised the work and got ideas mostly from previously read autonomy learning articles. 
This study applied a protocol designed by Kember. Which monitors and allocates work into 4 types, from the least to the highest, namely Habitual or non-reflection understanding and reflection levels, as well as the critical reflection. Each level has its pointers that help identification. The last level is habit or non-reflection, this occurs when students search for related materials on an assigned topic. In addition, they copy without thinking and attempting to comprehend the information. Sometimes they engage incomplete or partial plagiarism, which is frequently paraphrased or summarized without understanding the fundamental concept. The second level understands this occurs when the students rely on the lecturers' notes or textbook without reflecting on how these theories are related to the practical situation. Moreover, they failed to consider the manner this concept relates to their personal experiences. The third level is reflection, and its classification in writing form goes beyond that of understanding which involves presenting the applicable theory. The interpretation of this concept is connected with personal experiences. In practice, the situations faced are effectively discussed and related to the topic taught. At this level, students are expected to offer personal insights that exceed the theories reported in books.

SW1's reflection on the writing form goes beyond the understanding level by presenting the theoretical application. The concept was interpreted based on experiences. At this stage, SW1 provided personal insights. It was further reported that responsibility encourages students to be autonomous learners, and one important factor is motivation. For instance, assuming someone is not motivated to study independently, they find it difficult to engage in autonomy learning, especially in secondary students......... Nurturing their motivation is problematic, although it is an essential aspect of teaching that needs to be considered........(paused to reflect).... SW2 only gave a few definitions of learning autonomy by specific experts. There is no proof that it was described from their perspectives or turned their experiences into new knowledge, as it was not stated in detail. SW2 also engaged in partial plagiarism. Autonomy Learner in Indonesian is interpreted as independent teaching and learning activities (self-study). According to Cronbach, it is a relatively permanent change in one's behavior, understanding, or emotion (such as interests and attitudes) due to experience.................. Gagne (197) defines learning as a change in a person's disposition or capability that occurs within a certain period and it is not caused by growth processes. It was also revealed that there are 5 main varieties.

SW1 elaborated on each point that was planned and reflected on them for further development. SW2 failed to adhere to the rules of academic writing. The body paragraph was only based on some aspects of autonomy learning, such as the self-study program and its model. After reading SW2's body paragraph, it was concluded that there was no reflection in this stage. A semi-structured interview was conducted and used to answer the 2 research questions. Meanwhile, 10 items were related to the writing process and RW. Each participant was interviewed through Zoom meeting for about 20 minutes. All the activities were recorded during the interview and transcribed afterward. Some core information concerning the reason SW1 did not encounter serious writing problems, whereas SW2 struggled with this process, was reported in this study. Do you find reflective writing difficult? (SW1) "I love writing and reading because it is assumed that this helps develop my critical thinking skills. Reading supports the writing process as much information is acquired. It also helps to develop ones' writing style, improve grammatical understanding, and enlarge their vocabulary. Therefore, assuming one likes reading, they are likely not to have a problem with writing." That is SW1's opinion based on experiences.

SW1 is a blogger that enjoys sharing useful piece information in English with students, friends, or people that visit the blog regularly. It was also mentioned that writing while verbalizing their thought was a strenuous activity. Unfortunately, it also slightly affects SW1's writing quality. Usually, SW1 writes good pieces which develop their critical 
thinking. In this circumstance, SW1 was able to complete their writing, although the critical reflection level was not fully developed. When SW2 was asked a similar question the following response were obtained: (SW2): Writing is not something that I routinely engage in because I often find it difficult to develop my ideas in the middle of the process, perhaps it is due to the fact that I do not read a lot to broaden my horizon. I read when there is a writing task from my lecturer. These are the main problems that SW2 encountered during the writing process. First is a lack of reading and writing practice. There is a close interconnection between these two skills.

\section{Discussion}

Based on the indicators designed by Kember, SW1 is categorized in the reflection level and slightly grouped under critical reflection. SW1 was able to relate the autonomy learning concept to their personal experiences during classes (Hatlevik et al., 2018; Jeheman et al., 2019). Simultaneously, SW2 is at the level of habitual or non-reflection and understanding. Levels are not regarded as meaningful reflection (Kamelia, 2019; Khodabandehlou et al., 2012). At the habitual level, a person engages only in routine activities without thinking about them. Likewise, according to the analysis in this category, no reflective activity was involved as SW2 only described the written text. SW1 had read different articles, thereby being able to recognize the core scholarly arguments relevant to the topic, and initiated an outline to support the arguments because SW1 completely understands the writing process. SW1 carefully planned the written texts and tried to relate them to read articles and experiences previously. The writing was also revised and reread to ensure they were on the right track because it is a recursive procedure. SW1 paused to reflect before continuing, while SW2 has never been involved in these activities and is unaware that writing is a recursive process. In addition, SW2 rarely reread and revised their work. Writing strategies play an essential role in L2 development and distinguish between skilled and less-skilled writers (Amrina \& Sundari, 2021; Karaca \& Uysal, 2021). These are also significant issues influencing the students' writing quality (Alhassan \& Chen, 2019; Hill et al., 2020; Pen et al., 2020).

The findings of the research reported that some students encounter difficulties in reflective writing. A beneficial solution is to encourage students to practice writing in multiple contexts under an academic setting and get constant training supervised by their lecturer or teacher (Abrams \& Byrd, 2016; Flores, 2021; Wong \& Russak, 2020). Moreover, when reflexive writing assignments are effectively executed, it assists students to have a better knowledge of essential concepts, critically understand their professional identity, and create qualities for life-long learning (Staples et al., 2013; Sun et al., 2021).

\section{CONCLUSION}

Based on the results of data analysis, it can be concluded that the importance of integrating a focus on effective writing processes/sub-processes in academic writing and encouraging students to practice Reflective essays in various contexts by reading extensively while writing reflections.

\section{REFERENCES}

Abdel Latif, M. M. M. (2019). Using think-aloud protocols and interviews in investigating writers' composing processes: combining concurrent and retrospective data. International Journal of Research and Method in Education, 42(2), 111-123. https://doi.org/10.1080/1743727X.2018.1439003. 
Abednia, A., Hovassapian, A., Teimournezhad, S., \& Ghanbari, N. (2013). Reflective journal writing: Exploring in-service EFL teachers' perceptions. System, 41(1). https://doi.org/10.1016/j.system.2013.05.003.

Abrams, Z. I., \& Byrd, D. R. (2016). The effects of pre-task planning on L2 writing: Mindmapping and chronological sequencing in a 1st-year German class. System, 63. https://doi.org/10.1016/j.system.2016.08.011.

Alhassan, A., \& Chen, D. (2019). Investigating business EFL postgraduate student writing in a UK university : a qualitative study Investigating business EFL postgraduate student writing in a UK university: a qualitative study. Cogent Education, 6(1). https://doi.org/10.1080/2331186X.2019.1699741.

Alkubaidi, M. (2018). A Comparative Analysis of Writing Strategies and Performance in a Saudi University. Studies in Self-Access Learning Journal, 9, 425-443. https://doi.org/10.37237/090403.

Amrina, R., \& Sundari, H. (2021). Learning from Home Environment: Academic Writing Course for EFL Undergraduates through Google Classroom Application. Studies in English Language and Education, 8(2), 710-725. https://doi.org/10.24815/siele.v8i2.18374.

Anderson, H. L., Moore, J. E., \& Millar, B. C. (2021). Comparison of the readability of lay summaries and scientific abstracts published in CF Research News and the Journal of Cystic Fibrosis: Recommendations for writing lay summaries. Journal of Cystic Fibrosis, 1. https://doi.org/10.1016/j.jcf.2021.09.009.

Arter, M. L., Wallace, L. N., \& Shaffer, T. L. (2016). The Use of Reflective Journals to Stimulate Critical Thinking in the Academic Internship. Journal of Criminal Justice Education. https://doi.org/10.1080/10511253.2015.1109132.

Bahmani, S. (2016). Improved Critical Thinking in Students Using Current Events Journaling. International Journal of Sociology and Social Policy, 36(3/4). https://doi.org/10.1108/IJSSP-04-2015-0038.

Bjerkvik, L. K., \& Hilli, Y. (2019). Reflective writing in undergraduate clinical nursing education: A literature review. Nurse Education in Practice, 35. https://doi.org/10.1016/j.nepr.2018.11.013.

Caravella, E., \& Johnson, S. (2019). The Rebel Alliance: Analyzing Student Resistance in Digital Reflective Writing. Computers and Composition, 52. https://doi.org/10.1016/j.compcom.2019.01.011.

Cheng, M. W. T., \& Chan, C. K. Y. (2019). An experimental test: Using rubrics for reflective writing to develop reflection. Studies in Educational Evaluation, 61. https://doi.org/10.1016/j.stueduc.2019.04.001.

Farahian, M., Avarzamani, F., \& Rajabi, Y. (2021). Reflective thinking in an EFL Writing course: To what level do portfolios improve reflection in writing? Thinking Skills and Creativity, 39. https://doi.org/10.1016/j.tsc.2020.100759.

Flores, J. A. A. (2021). The semiotics of writing: How adult L2 learners with emergent literacy make meaning in assessment texts through writing. Journal of Second Language Writing, 51. https://doi.org/10.1016/j.jslw.2021.100793.

Guo, X., \& Huang, L. S. (2018). Are L1 and L2 strategies transferable? An exploration of the L1 and L2 writing strategies of Chinese graduate students. Language Learning Journal, O(0), 1-23. https://doi.org/10.1080/09571736.2018.1435710.

Hashemi, Z., \& Mirzaei, T. (2015). Conversations of the Mind: The Impact of Journal Writing on Enhancing EFL Medical Students' Reflections, Attitudes, and Sense of Self. Procedia - Social and Behavioral Sciences, 199. https://doi.org/10.1016/j.sbspro.2015.07.493.

Hatlevik, O. E., Throndsen, I., Loi, M., \& Gudmundsdottir, G. B. (2018). Students' ICT self- 
efficacy and computer and information literacy: Determinants and relationships. Computers and Education, 118(November 2017), 107-119. https://doi.org/10.1016/j.compedu.2017.11.011.

Hill, C., Khoo, S., \& Hsieh, Y.-C. (2020). An investigation into the learning transfer of English for specific Academic Purposes (ESAP) writing skills of students in Singapore. Journal of English for Academic Purposes, 46. https://doi.org/10.1016/j.jeap.2020.100908.

Iman, T. R. (2020). The Interference of Indonesian Language on English. Journal of Languages and Language Teaching (JOLLT ), 8(2), 170-182. https://doi.org/10.33394/jollt.v8i2.2466.

Jeheman, A. A., Gunur, B., \& Jelatu, S. (2019). Pengaruh Pendekatan Matematika Realistik terhadap Pemahaman Konsep Matematika Siswa. Mosharafa: Jurnal Pendidikan Matematika, 8(2), 191-202. https://doi.org/10.31980/mosharafa.v8i2.454.

Johnson, M. D. (2020). Planning in L1 and L2 writing: Working memory, process, and product. Language Teaching, 53(4), 433-445. https://doi.org/10.1017/S0261444820000191.

K. W. Chu, S., Wu, J., W. S. Kwan, C., \& H. Y. Lai, J. (2019). Wiki-based Collaborative Writing: A Comparative Study on First and Second Language Writing among Chinese Secondary Students. International Journal of Modern Education and Computer Science, 11(1), 1-10. https://doi.org/10.5815/ijmecs.2019.01.01.

Kamelia, K. (2019). Using Video as Media of Teaching in English Language Classroom: Expressing Congratulation and Hopes. Utamax: Journal of Ultimate Research and Trends in Education, 1(1), 34-38. https://doi.org/10.31849/utamax.v1i1.2742.

Karaca, M., \& Uysal, H. H. (2021). The development and validation of an inventory on English writing teacher beliefs. Assessing Writing, 47. https://doi.org/10.1016/j.asw.2020.100507.

Khodabandehlou, M., Jahandar, S., Seyedi, G., \& Abadi, R. M. D. (2012). The impact of selfdirected learning strategies on reading comprehension. International Journal of Scientific \& Engineering Research Volume, 3(7), 1-9.

Liu, G. (2015). Investigating the English Writing Strategies Used by Chinese Senior High School Students. Theory and Practice in Language Studies, 5(4), 844. https://doi.org/10.17507/tpls.0504.21.

Pen, T. T.-L., Marchand, C., Léocadie, M., \& Rothan-Tondeur, M. (2020). Reflective writing: Implementation and learning perception from students and teachers of French nursing schools. Nurse Education in Practice, 49. https://doi.org/10.1016/j.nepr.2020.102921.

Stanton, A. D., \& Stanton, W. W. (2017). Using journaling to enhance learning and critical thinking in a retailing course. Journal for Advancement of Marketing Education. https://doi.org/10.29408/veles\%20journal.v4i1.2020.

Staples, S., Egbert, J., Biber, D., \& McClair, A. (2013). Formulaic sequences and EAP writing development: Lexical bundles in the TOEFL iBT writing section. Journal of English for Academic Purposes, 12(3). https://doi.org/10.1016/j.jeap.2013.05.002.

Sun, T., Wang, C., Lambert, R. G., \& Liu, L. (2021). Relationship between second language English writing self-efficacy and achievement: A meta-regression analysis. Journal of Second Language Writing, 53. https://doi.org/10.1016/j.jslw.2021.100817.

Szenes, E., \& Tilakaratna, N. (2021). Deconstructing critical reflection in social work and business: Negotiating emotions and opinions in reflective writing. Journal of English for Academic Purposes, 49. https://doi.org/10.1016/j.jeap.2020.100931.

Thevasigamoney, A. F., \& Yunus, M. M. (2014). A Glimpse into E-Mail Dialogue Journal Writing (EDJW) and Writing Anxiety among Gifted Learners. Procedia - Social and 
Behavioral Sciences, 123. https://doi.org/10.1016/j.sbspro.2014.01.1423.

Wang, Y. (2012). Differences in L1 and L2 academic writing. Theory and Practice in Language Studies, 2(3), 637-641. https://doi.org/10.4304/tpls.2.3.637-641.

Weaver, R. M., \& Mulgrew, K. E. (2021). The effectiveness of positive appearance and functionality reflective writing tasks on state body image and response to idealised media exposure among 35-60 year-old women. Body Image, 37. https://doi.org/10.1016/j.bodyim.2021.02.008.

Wei, X. (2020). Assessing the metacognitive awareness relevant to L1-to-L2 rhetorical transfer in L2 writing: The cases of Chinese EFL writers across proficiency levels. Assessing Writing, 44(September 100452. https://doi.org/10.1016/j.asw.2020.100452.

Wingate, U., \& Harper, R. (2021). Completing the first assignment: A case study of the writing processes of a successful and an unsuccessful student. Journal of English for Academic Purposes, 49, 100948. https://doi.org/10.1016/j.jeap.2020.100948.

Wong, K. S. R., \& Russak, S. (2020). Hong Kong Cantonese L1 preschool children's name writing in English L2. Cognitive Development, 56. https://doi.org/10.1016/j.cogdev.2020.100957. 